\title{
Insomnia symptoms and risk of cardiovascular diseases among 0.5 million adults
}

\section{A 10-year cohort}

Bang Zheng, MD, MSc, Canqing Yu, PhD, Jun Lv, PhD, Yu Guo, MSc, Zheng Bian, MSc, Mi Zhou, BSc, Ling Yang, PhD, Yiping Chen, DPhil, Xiaojun Li, BSc, Ju Zou, BSc, Feng Ning, PhD, Junshi Chen, MD, Zhengming Chen, DPhil, and Liming Li, MD, on behalf of the China Kadoorie Biobank Collaborative Group Neurology ${ }^{\circledR}$ 2019;93:e2110-e2120. doi:10.1212/WNL.0000000000008581

\begin{abstract}
Objective

To examine the associations of individual insomnia symptoms with risks of incident cardiocerebral vascular diseases (CVD) and possible moderating factors among Chinese adults.

\section{Methods}

The China Kadoorie Biobank is a prospective cohort study that recruited participants from 10 areas across China. Data from 487,200 adults 30 to 79 years of age who were free of stroke, coronary heart disease, and cancer at baseline were analyzed. Three insomnia symptoms were assessed with self-reported difficulties in initiating or maintaining sleep, early morning awakening, and daytime dysfunction for at least $3 \mathrm{~d} / \mathrm{wk}$ at baseline. Incidences of CVD were followed up through disease registries and national health insurance databases until 2016.
\end{abstract}

\section{Results}

During a median of 9.6 years of follow-up, 130,032 cases of CVD were documented. Cox regressions showed that 3 insomnia symptoms were associated with increased risk of total CVD, with respective adjusted hazard ratios (HRs) and 95\% confidence intervals (CIs) of 1.09 (95\% CI 1.07-1.11), 1.07 (95\% CI 1.05-1.09), and 1.13 (95\% CI 1.09-1.18). Participants with individual symptoms also had higher risks of ischemic heart disease (IHD; HR 1.13, 1.09, and 1.17 ) and ischemic stroke but not hemorrhagic stroke. Participants with all 3 symptoms were at an $18 \%, 22 \%$, or $10 \%$ higher risk of CVD, IHD, or ischemic stroke compared to nonsymptomatic adults. Associations between 3 symptoms and CVD incidence were consistently stronger in younger adults or those without baseline hypertension ( $p$ for interaction $<0.05$ ).

\section{Conclusions}

Individual and coexisting insomnia symptoms are independent risk factors for CVD incidence, especially among young adults or adults who have not developed hypertension.

\author{
Correspondence \\ Dr. L. Li \\ Imlee@vip.163.com \\ or Dr. Yu \\ yucanqing@pku.edu.cn
}

\section{MORE ONLINE}

- CME Course

NPub.org/cmelist 


\section{Glossary}

$\mathbf{B M I}=$ body mass index $\mathbf{C H D}=$ coronary heart disease $; \mathbf{C I}=$ confidence interval $\mathbf{C K B}=$ China Kadoorie Biobank; $\mathbf{C V D}=$ cardio-cerebral vascular disease; DDF = daytime dysfunction; DIMS = difficulties in initiating or maintaining sleep; EMA = early morning awakening; HR = hazard ratio; ICD-10 = International Classification of Diseases, 10 th Revision; IHD = ischemic heart disease; $\mathbf{M I}=$ myocardial infarction.

\section{Does Insomnia Increase the Risk of Cardiocerebrovascular Disease?}

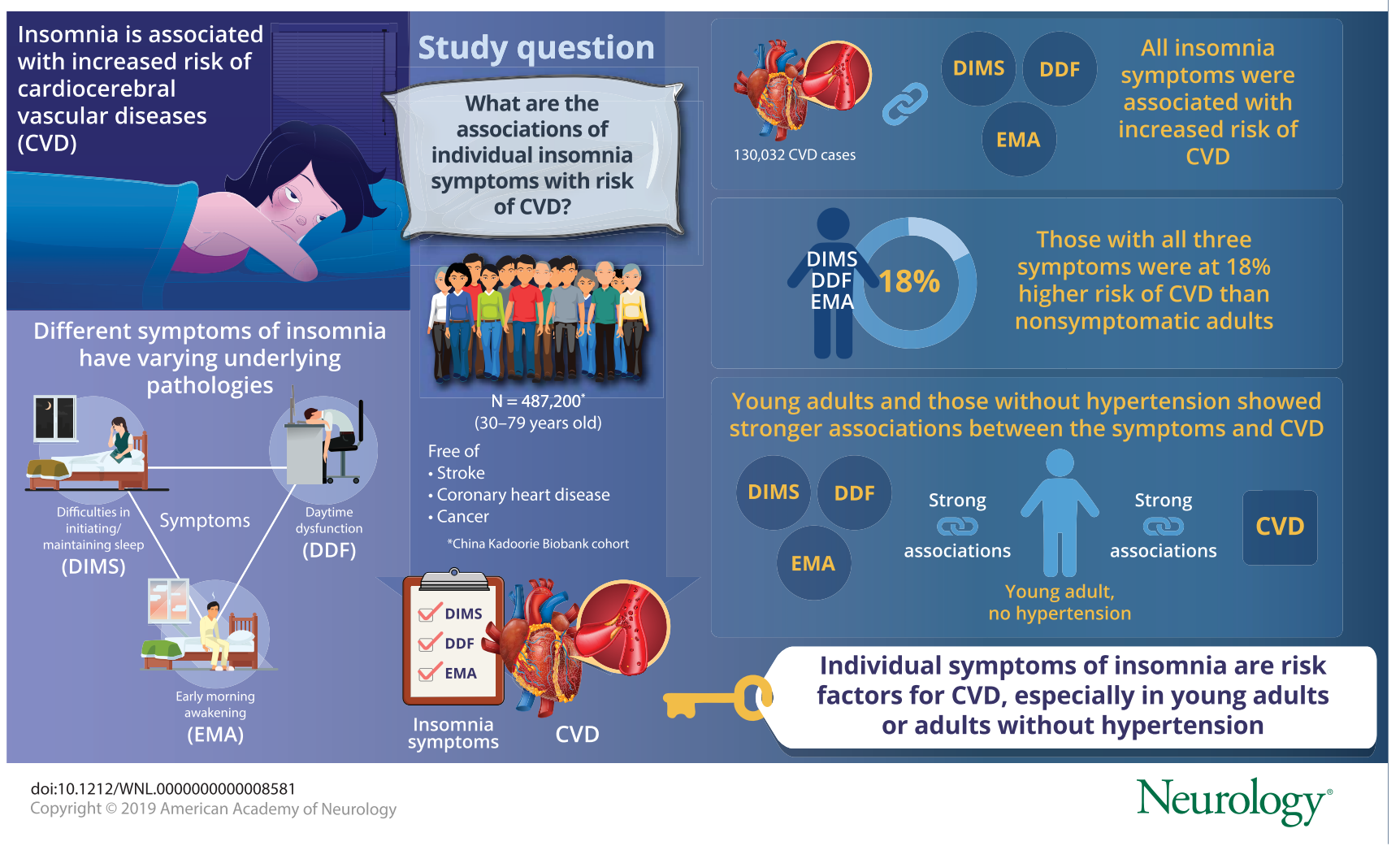

Insomnia, characterized by poor sleep quality of having difficulties in initiating or maintaining sleep (DIMS) and often accompanied by daytime dysfunction (DDF), is the commonest sleep disorder and the second most prevalent mental disorder throughout the world. ${ }^{1-3}$ According to the China Chronic Disease and Risk Factor Surveillance Study, 35.7\% of Chinese residents 15 to 69 years of age reported poor sleep quality. ${ }^{4}$ Previous studies have shown that insomnia has adverse effects on physical health and mental health in the general population. ${ }^{5}$

Emerging evidence from prospective studies suggested that insomnia disorder is associated with increased risks of cardiocerebral vascular diseases (CVD). ${ }^{6-8} \mathrm{~A}$ recent meta-analysis of 17 cohort studies indicated that insomnia significantly increased CVD mortality (hazard ratio [HR] 1.33, 95\% confidence interval [CI $]$ 1.13-1.57) and risks of individual types of CVD, including myocardial infarction (MI), coronary heart disease (CHD), and stroke. ${ }^{9}$

However, the definitions of insomnia in most previous cohort studies are not clear enough or are simply based on the symptom of having difficulties initiating sleep, ${ }^{9,10}$ while other insomnia symptoms have not been fully investigated. Compared with clinically diagnosed insomnia meeting the frequency, duration, and severity criteria, individual insomnia symptoms are easier to assess in large-scale studies and population screenings and thus have more public health significance. Because different insomnia symptoms are related to distinct underlying mechanisms and pathologic changes (e.g., early morning awakening [EMA] reflects circadian rhythmic disruption rather than a delay of the circadian cycle phase), ${ }^{11,12}$ it is possible that their effects on CVD risks could vary dramatically. Moreover, few studies have explored the associations between coexisting insomnia symptoms and CVD incidences. There is also limited and controversial evidence regarding whether the insomnia-CVD associations vary by age, sex, or other population characteristics. ${ }^{7,8,13}$ Therefore, to comprehensively clarify the relationships between individual insomnia symptoms and CVD incidence and potential effect modifiers, this study was conducted using the large-scale cohort data from the China Kadoorie Biobank (CKB) Study. ${ }^{14}$ 


\section{Methods}

\section{Study population}

The CKB Study is an ongoing population-based prospective study that aims to assess the complex interplay of lifestyle, environmental, and genetic factors as determinants of chronic diseases. ${ }^{14}$ Details of this study have been previously reported. ${ }^{15}$ Briefly, the CKB cohort included 512,715 adults (age 30-79 years) from 10 geographically diverse areas across China who completed a baseline survey during 2004 to 2008 and have been followed up since.

In the present study, individuals were excluded from analyses if they had a history of stroke $(\mathrm{n}=8,884), \mathrm{CHD}(\mathrm{n}=15,472)$, or cancer $(\mathrm{n}=2,578)$ at baseline. After exclusions, 487,200 participants (199,241 men and 287,959 women) remained in the analyses.

\section{Assessment of insomnia symptoms}

The baseline survey of CKB study included questions pertaining to specific insomnia symptoms for at least $3 \mathrm{~d} / \mathrm{wk}$ in the past month, the frequency threshold of which was in compliance with established clinical diagnostic criteria. ${ }^{16}$ Subjects were classified as having DIMS if they reported having trouble falling asleep (sleep onset latency $\geq 30$ minutes) after going to bed or waking up in the middle of the night; those who reported waking up too early and not be able to get back to sleep were classified as having EMA; those who reported having trouble keeping sober-minded during daytime because of bad sleep were classified as having DDF; and those who reported 1 or more of the 3 symptoms were classified as having any insomnia symptoms.

Information on covariates was obtained from the baseline survey and physical examination, ${ }^{14,15}$ including sociodemographic characteristics, lifestyle factors, body mass index (BMI; weight in kilograms divided by height in meters squared), medical history, other sleep variables, and mental health status.

\section{Ascertainment of CVD outcomes}

Information on CVD incidence was collected through linkages with established disease registries, the new national health insurance claim databases, and local residential records. ${ }^{15}$ Electronic linkage to the national health insurance databases has covered $95 \%$ of the participants in 2013 and has been renewed annually. To minimize underreporting of diseases and to identify those who were lost to follow-up, participants not linked to the health insurance databases were actively followed up annually by staff to ascertain their status of hospital admission, death, or moving out of the study area.

Trained staff blinded to baseline information of participants coded all diagnoses and deaths that occurred during follow-up using the ICD-10. The main outcomes of interest included the incidences of CVD (I00-I99); ischemic heart disease (IHD, I20-I25) and acute MI (I21); and stroke (I60-I61; I63-I64), hemorrhagic stroke (I61), and ischemic stroke (I63).

\section{Statistical analysis}

Descriptive analyses were conducted to compare the distributions of baseline characteristics among participants with and without specific insomnia symptoms. The differences of means or proportions of baseline variables between groups were estimated with general linear regression or binary/multinomial logistic regression models, respectively, controlling for age, sex, and study areas. Follow-up time of each participant was defined as the time interval from the baseline survey (2004-2008) to the diagnosis of the specific outcome, death resulting from any cause, loss to follow-up, or December 31, 2016, whichever occurred first. Cox proportional hazard models were used to estimate the HRs and 95\% CIs for the associations between each of the 3 insomnia symptoms (DIMS, EMA, DDF) and CVD outcomes, with age as the underlying time scale. To account for the group-specific effect, the models were stratified jointly by sex, 10 study areas, and age at baseline in 5-year intervals.

The Cox regression models were adjusted for established and potential confounding factors sequentially. We included age at baseline (continuous) in the first model and additionally adjusted for the following covariates in the second model: level of education (no formal school, primary school, middle school, high school, college, or university or higher); annual household income $(<2,500,2,500-4,999$, $5,000-9,999,10,000-19,999,20,000-34,999$, or $\geq 35,000$ $\mathrm{RMB}$ ); marital status (married, widowed, divorced or separated, or never married); alcohol consumption (not weekly drinking, former regular drinker, weekly but not daily drinking, daily drinker of $<15,15-29,30-59$, or $\geq 60 \mathrm{~g} / \mathrm{d}$ ); smoking status (never/occasional smoker, former smoker, regular smoker of $1-14,15-24$, or $\geq 25$ cigarettes/d); tea consumption (never/almost never, occasionally, only at certain seasons, every month but less than weekly, or usually at least once a week); physical activity level in metabolic equivalent of task-hours per day (continuous); intake frequencies of red meat, fresh fruits, and fresh vegetables (daily, 4-6 d/wk, 1-3 d/wk, monthly, or rarely/never); and family history of heart attack and stroke (presence or absence). We further adjusted for possible mediators/confounders in the third model, including BMI (<24.0, 24.0-27.9, $\geq 28.0 \mathrm{~kg} /$ $\mathrm{m}^{2}$ ), prevalent hypertension and diabetes mellitus at baseline (presence or absence), frequent use of sleep aid medications (frequent users or not), frequency of snoring during sleep (frequently, sometimes, never/do not know), and mental health status (having depression or anxiety symptoms or not). The interaction terms between different insomnia symptoms were then tested in the full model. Sexspecific modeling was also conducted to examine the possible sex heterogeneity in the insomnia-CVD associations. Furthermore, we estimated the HRs of CVD incidences by the number of insomnia symptoms (taking participants with no symptoms as the reference group) and any insomnia symptoms following the same modeling procedures. Tests for linear trend were conducted by modeling the number of insomnia symptoms as a continuous variable. 
To examine the robustness of the main findings, we also conducted several sensitivity analyses: additionally adjusting for the 3 insomnia symptoms mutually to estimate their associations with CVD risks independently of each other; additionally adjusting for occupation, household size, menopausal status (for women only; premenopausal, perimenopausal, or postmenopausal), history of chronic obstructive pulmonary disease (presence or absence), diseases causing chronic pain (peptic ulcer, gallstone/gallbladder disease, rheumatoid arthritis), and psychiatric disorders; excluding frequent users of sleep aid medication; and excluding participants developing or dying of CVDs during the first 2 years of follow-up to rule out the possibility of reverse causality.

Subgroup analyses were further conducted to examine possible moderating effects of baseline characteristics on the insomnia-CVD associations. We estimated the associations among prespecified baseline subgroups based on age $(<50$,
$50-59$, or $\geq 60$ years), BMI (<24.0, 24.0-27.9, or $\geq 28.0 \mathrm{~kg}$ / $\mathrm{m}^{2}$ ), level of physical activity (categorized with tertile cutoffs), prevalent hypertension and diabetes mellitus at baseline (presence or absence), and sleep duration $(<7,7-9$, or $>9$ hours, based on the National Sleep Foundation's recommendations ${ }^{17}$ ). Effect modifications by these variables were tested by comparing the models with and without corresponding interaction terms using likelihood ratio tests.

Statistical analyses were performed with Stata (version 14, StataCorp, College Station, TX). All statistical tests were 2 sided, and the statistical significance was defined as $p<0.05$.

\section{Standard protocol approvals, registrations, and patient consents}

The study was approved by the Ethical Review Committee of the Chinese Center for Disease Control and Prevention (Beijing, China) and the Oxford Tropical Research Ethics

Table 1 Baseline characteristics of participants with and without insomnia symptoms

\begin{tabular}{|c|c|c|c|c|c|c|c|}
\hline \multirow[b]{2}{*}{ Characteristics } & \multirow[b]{2}{*}{ Overall } & \multicolumn{2}{|l|}{ DIMS } & \multicolumn{2}{|l|}{ EMA } & \multicolumn{2}{|l|}{ DDF } \\
\hline & & No & Yes & No & Yes & No & Yes \\
\hline Participants, $\mathbf{n}$ & 487,200 & 432,073 & 55,127 & 436,509 & 50,691 & 476,399 & 10,801 \\
\hline Male, \% & 199,241 & 42.0 & 32.1 & 41.9 & 32.0 & 41.2 & 26.3 \\
\hline Urban area, \% & 210,136 & 43.9 & 36.9 & 43.6 & 38.8 & 43.2 & 38.8 \\
\hline Age, y & 51.0 & 50.8 & 53.2 & 50.7 & 54.3 & 51.0 & 52.2 \\
\hline \multicolumn{8}{|l|}{ Education level, \% } \\
\hline Primary school or below & 247,620 & 50.7 & 52.0 & 50.5 & 53.6 & 50.8 & 51.9 \\
\hline Middle or high school & 211,963 & 43.5 & 43.4 & 43.7 & 42.0 & 43.5 & 43.6 \\
\hline College or above & 27,617 & 5.8 & 4.6 & 5.8 & 4.4 & 5.7 & 4.5 \\
\hline \multicolumn{8}{|l|}{ Annual household income, \% } \\
\hline$<10,000$ RMB & 138,119 & 28.0 & 31.0 & 27.9 & 32.3 & 28.2 & 32.6 \\
\hline 10,000-19,999 RMB & 140,612 & 28.8 & 29.5 & 28.9 & 28.5 & 28.9 & 28.8 \\
\hline$\geq 20,000$ RMB & 208,469 & 43.2 & 39.5 & 43.2 & 39.2 & 42.9 & 38.6 \\
\hline Married, \% & 442,798 & 91.2 & 88.6 & 91.2 & 88.7 & 90.9 & 88.5 \\
\hline Current smoker, \% & 130,335 & 26.6 & 28.3 & 26.9 & 25.6 & $26.8^{a}$ & $26.9^{a}$ \\
\hline Current drinker, $\%$ & 73,634 & $15.1^{\mathrm{a}}$ & $15.3^{a}$ & 15.0 & 15.9 & 15.1 & 14.1 \\
\hline Physical activity level, MET-h/d & 21.6 & 21.6 & 21.5 & 21.5 & 21.7 & 21.6 & 21.3 \\
\hline $\mathrm{BMI}, \mathrm{kg} / \mathrm{m}^{2}$ & 23.6 & 23.7 & 23.2 & 23.6 & 23.2 & 23.6 & 23.2 \\
\hline Hypertension, \% & 164,311 & 33.8 & 33.2 & $33.7^{\mathrm{a}}$ & $33.7^{\mathrm{a}}$ & $33.7^{\mathrm{a}}$ & $33.3^{\mathrm{a}}$ \\
\hline Diabetes mellitus, \% & 26,161 & 5.3 & 6.0 & 5.3 & 5.7 & 5.3 & 6.6 \\
\hline Depression symptom, \% & 14,390 & 2.2 & 8.9 & 2.3 & 8.7 & 2.7 & 14.7 \\
\hline Anxiety symptom, \% & 2,800 & 0.4 & 2.0 & 0.4 & 2.1 & 0.5 & 4.2 \\
\hline
\end{tabular}

Abbreviations: $\mathrm{BMI}=$ body mass index; DDF = daytime dysfunction; DIMS = difficulties in initiating or maintaining sleep; EMA = early morning awakening; MET = metabolic equivalent of task.

${ }^{a}$ All variables were adjusted for age, sex, and 10 study areas as appropriate. The distributions of all variables were significantly different between participants with and those without specific insomnia symptoms $(p<0.05)$ except for those indicated. 
Table $2 \mathrm{HR}(95 \% \mathrm{Cl})$ of total and subtypes of CVD incidence according to insomnia symptoms among 487,200 participants

\begin{tabular}{|c|c|c|c|c|c|c|}
\hline \multirow[b]{2}{*}{ Endpoints } & \multicolumn{2}{|l|}{ DIMS } & \multicolumn{2}{|l|}{ EMA } & \multicolumn{2}{|l|}{ DDF } \\
\hline & No & Yes & No & Yes & No & Yes \\
\hline \multicolumn{7}{|l|}{ Total CVD } \\
\hline Person-years & $3,837,995$ & 479,508 & $3,880,083$ & 437,420 & $4,220,713$ & 96,791 \\
\hline No. of cases & 112,382 & 17,650 & 113,282 & 16,750 & 126,613 & 3,419 \\
\hline Model 1 & 1.00 & $1.10(1.08-1.12)$ & 1.00 & $1.08(1.06-1.10)$ & 1.00 & $1.18(1.14-1.22)$ \\
\hline Model 2 & 1.00 & $1.09(1.08-1.11)$ & 1.00 & $1.07(1.06-1.09)$ & 1.00 & $1.17(1.13-1.21)$ \\
\hline Model 3 & 1.00 & $1.09(1.07-1.11)$ & 1.00 & $1.07(1.05-1.09)$ & 1.00 & $1.13(1.09-1.18)$ \\
\hline \multicolumn{7}{|l|}{ IHD } \\
\hline Person-years & $4,180,654$ & 530,043 & $4,225,577$ & 485,119 & $4,605,442$ & 105,255 \\
\hline No. of cases & 34,509 & 5,839 & 34,884 & 5,464 & 39,127 & 1,221 \\
\hline Model 1 & 1.00 & $1.14(1.11-1.18)$ & 1.00 & $1.11(1.07-1.14)$ & 1.00 & $1.23(1.17-1.31)$ \\
\hline Model 2 & 1.00 & $1.14(1.11-1.17)$ & 1.00 & $1.11(1.08-1.14)$ & 1.00 & $1.22(1.15-1.29)$ \\
\hline Model 3 & 1.00 & $1.13(1.09-1.16)$ & 1.00 & $1.09(1.06-1.13)$ & 1.00 & $1.17(1.10-1.24)$ \\
\hline \multicolumn{7}{|l|}{ Acute MI } \\
\hline Person-years & $4,297,061$ & 549,609 & $4,343,477$ & 503,193 & $4,737,178$ & 109,492 \\
\hline No. of cases & 4,960 & 830 & 5,005 & 785 & 5,652 & 138 \\
\hline Model 1 & 1.00 & $1.13(1.04-1.21)$ & 1.00 & $1.08(1.00-1.16)$ & 1.00 & $1.10(0.93-1.31)$ \\
\hline Model 2 & 1.00 & $1.10(1.02-1.18)$ & 1.00 & $1.06(0.99-1.15)$ & 1.00 & $1.06(0.90-1.26)$ \\
\hline Model 3 & 1.00 & $1.09(1.01-1.18)$ & 1.00 & $1.06(0.98-1.14)$ & 1.00 & $1.02(0.86-1.22)$ \\
\hline \multicolumn{7}{|l|}{ Stroke } \\
\hline Person-years & $4,174,609$ & 530,465 & $4,219,831$ & 485,243 & $4,599,496$ & 105,578 \\
\hline No. of cases & 39,107 & 6,209 & 39,285 & 6,031 & 44,051 & 1,265 \\
\hline Model 1 & 1.00 & $1.07(1.04-1.10)$ & 1.00 & $1.08(1.05-1.11)$ & 1.00 & $1.13(1.07-1.20)$ \\
\hline Model 2 & 1.00 & $1.05(1.02-1.08)$ & 1.00 & $1.06(1.03-1.09)$ & 1.00 & $1.11(1.05-1.17)$ \\
\hline Model 3 & 1.00 & $1.05(1.02-1.08)$ & 1.00 & $1.05(1.02-1.08)$ & 1.00 & $1.08(1.02-1.14)$ \\
\hline
\end{tabular}


Table 2 HR (95\% Cl) of total and subtypes of CVD incidence according to insomnia symptoms among 487,200 participants (continued)

\begin{tabular}{|c|c|c|c|c|c|c|}
\hline \multirow[b]{2}{*}{ Endpoints } & \multicolumn{2}{|l|}{ DIMS } & \multicolumn{2}{|l|}{ EMA } & \multicolumn{2}{|l|}{ DDF } \\
\hline & No & Yes & No & Yes & No & Yes \\
\hline \multicolumn{7}{|c|}{ Hemorrhagic stroke } \\
\hline Person-years & $4,290,017$ & 548,937 & $4,336,759$ & 502,195 & $4,729,649$ & 109,305 \\
\hline No. of cases & 7,734 & 1,209 & 7,717 & 1,226 & 8,724 & 219 \\
\hline Model 1 & 1.00 & $1.02(0.96-1.09)$ & 1.00 & $1.04(0.98-1.11)$ & 1.00 & $1.06(0.93-1.22)$ \\
\hline Model 2 & 1.00 & $0.99(0.93-1.05)$ & 1.00 & $1.00(0.94-1.06)$ & 1.00 & $1.02(0.89-1.17)$ \\
\hline Model 3 & 1.00 & $0.99(0.93-1.05)$ & 1.00 & $1.00(0.94-1.06)$ & 1.00 & $1.01(0.88-1.16)$ \\
\hline \multicolumn{7}{|l|}{ Ischemic stroke } \\
\hline Person-years & $4,189,663$ & 532,427 & $4,234,864$ & 487,227 & $4,616,167$ & 105,923 \\
\hline No. of cases & 32,394 & 5,185 & 32,593 & 4,986 & 36,506 & 1,073 \\
\hline Model 1 & 1.00 & $1.09(1.06-1.12)$ & 1.00 & $1.09(1.06-1.12)$ & 1.00 & $1.15(1.08-1.22)$ \\
\hline Model 2 & 1.00 & $1.07(1.04-1.10)$ & 1.00 & $1.08(1.04-1.11)$ & 1.00 & $1.12(1.06-1.19)$ \\
\hline Model 3 & 1.00 & $1.06(1.03-1.10)$ & 1.00 & $1.07(1.04-1.10)$ & 1.00 & $1.09(1.02-1.16)$ \\
\hline
\end{tabular}

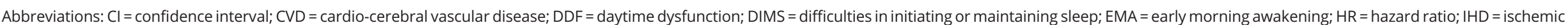
heart disease; $\mathrm{Ml}=$ myocardial infarction.

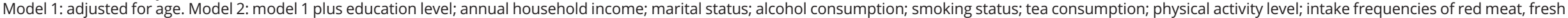

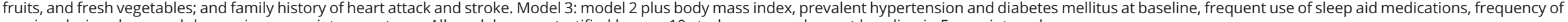
snoring during sleep, and depression or anxiety symptoms. All models were stratified by sex, 10 study areas, and age at baseline in 5-year intervals. 
Committee, University of Oxford (UK). All study participants provided written informed consent.

\section{Data availability}

Cohort description and questionnaires are available at p3gobservatory.org/questionnaire/list.htm. Statistical code is available from Dr. Yu (e-mail, yucanqing@pku.edu.cn). For the data set, please refer to the CKB Study website (ckbiobank.org) for data access policy and procedures.

\section{Results}

\section{Baseline characteristics of participants by insomnia symptoms}

Among the 487,200 participants included in the analyses, $11.3 \%$ reported having the symptom of DIMS, $10.4 \%$ reported having EMA, and 2.2\% reported having DDF. Compared with participants without specific insomnia symptoms, those with DIMS, EMA, or DDF were older, more likely to be female, not married, and from rural area; had lower education level, household income, and BMI; were more likely to report a history of diabetes mellitus; and had depression or anxiety symptoms $(p<0.05$, table 1$)$.

\section{Associations of insomnia symptoms with total and specific types of CVD incidence}

During a median follow-up of 9.6 years $(4,317,504$ total person-years), 130,032 cases of total CVD incidence, 40,348 cases of IHD, and 45,316 cases of stroke incidence were documented. After full adjustment for potential confounders, the insomnia symptoms of DIMS, EMA, and DDF were all associated with increased risks of total CVD incidence, and the respective HRs (95\% CIs) were 1.09
(1.07-1.11), 1.07 (1.05-1.09), and 1.13 (1.09-1.18) (table 2).

Participants with DIMS, EMA, or DDF also had higher risks of IHD incidence compared with those without corresponding symptoms (HR 1.13, 1.09, and 1.17, $p<0.05$ ). Only DIMS was associated with higher risk of acute MI (HR 1.09, $p<0.05$ ). All 3 symptoms were associated with slightly increased risks of total stroke incidence (HR 1.05, 1.05, and 1.08) and ischemic stroke incidence (HR 1.06, 1.07, and 1.09, $p<0.05$ ). No associations were observed between the 3 symptoms and hemorrhagic stroke incidence $(p>0.05$, table 2$)$. No interactions between insomnia symptoms on CVD risks were detected $(p>0.05)$.

In the sensitivity analyses, the estimates did not change appreciably after adjusting for additional covariates, excluding participants with frequent use of sleep aid medications, or excluding participants developing or dying of CVDs during the first 2 years of follow-up (data not shown). However, the association between DDF and ischemic stroke incidence was no longer significant (HR 1.04, 95\% CI 0.97-1.11) after additionally controlling for DIMS and EMA.

Sex-specific modeling showed that associations between DIMS, EMA, DDF, and total CVD incidence were consistent among male and female participants (table 3). However, as for specific types of CVD, the association between DDF and IHD incidence was significantly stronger in women than in men. A similar pattern was found for the association between EMA and acute MI incidence ( $p$ for interaction $<0.05$ ). Moreover, associations of DDF with the incidence of stroke and its subtypes were identified only in male participants, although the sex heterogeneity was not statistically significant ( $p$ for interaction $>0.05$ ).

Table $3 \mathrm{HR}(95 \% \mathrm{Cl})$ of total and subtypes of CVD incidence according to insomnia symptoms stratified by sex ${ }^{\mathrm{a}}$

\begin{tabular}{|c|c|c|c|c|c|c|c|c|c|}
\hline \multirow[b]{2}{*}{ Endpoints } & \multicolumn{3}{|l|}{ DIMS } & \multicolumn{3}{|l|}{ EMA } & \multicolumn{3}{|l|}{ DDF } \\
\hline & Male & Female & $\begin{array}{l}p \text { for } \\
\text { Interaction }^{b}\end{array}$ & Male & Female & $\begin{array}{l}p \text { for } \\
\text { Interaction }^{b}\end{array}$ & Male & Female & $\begin{array}{l}p \text { for } \\
\text { Interaction }^{b}\end{array}$ \\
\hline Total CVD & $\begin{array}{l}1.11 \\
(1.08-1.14)\end{array}$ & $\begin{array}{l}1.08 \\
(1.06-1.10)\end{array}$ & 0.033 & $\begin{array}{l}1.05 \\
(1.02-1.09)\end{array}$ & $\begin{array}{l}1.08 \\
(1.05-1.10)\end{array}$ & 0.868 & $\begin{array}{l}1.18 \\
(1.10-1.26)\end{array}$ & $\begin{array}{l}1.12 \\
(1.08-1.17)\end{array}$ & 0.478 \\
\hline IHD & $\begin{array}{l}1.13 \\
(1.07-1.19)\end{array}$ & $\begin{array}{l}1.12 \\
(1.09-1.17)\end{array}$ & 0.530 & $\begin{array}{l}1.07 \\
(1.02-1.13)\end{array}$ & $\begin{array}{l}1.11 \\
(1.07-1.15)\end{array}$ & 0.118 & $\begin{array}{l}1.11 \\
(0.98-1.26)\end{array}$ & $\begin{array}{l}1.19 \\
(1.11-1.27)\end{array}$ & 0.042 \\
\hline Acute MI & $\begin{array}{l}1.05 \\
(0.94-1.18)\end{array}$ & $\begin{array}{l}1.12 \\
(1.01-1.25)\end{array}$ & 0.099 & $\begin{array}{l}0.98 \\
(0.87-1.11)\end{array}$ & $\begin{array}{l}1.12 \\
(1.00-1.24)\end{array}$ & 0.009 & $\begin{array}{l}0.87 \\
(0.64-1.19)\end{array}$ & $\begin{array}{l}1.11 \\
(0.89-1.38)\end{array}$ & 0.174 \\
\hline Stroke & $\begin{array}{l}1.06 \\
(1.01-1.11)\end{array}$ & $\begin{array}{l}1.04 \\
(1.00-1.08)\end{array}$ & 0.396 & $\begin{array}{l}1.03 \\
(0.99-1.08)\end{array}$ & $\begin{array}{l}1.07 \\
(1.03-1.11)\end{array}$ & 0.434 & $\begin{array}{l}1.18 \\
(1.06-1.31)\end{array}$ & $\begin{array}{l}1.04 \\
(0.97-1.12)\end{array}$ & 0.265 \\
\hline $\begin{array}{l}\text { Hemorrhagic } \\
\text { stroke }\end{array}$ & $\begin{array}{l}1.06 \\
(0.96-1.16)\end{array}$ & $\begin{array}{l}0.93 \\
(0.86-1.02)\end{array}$ & 0.089 & $\begin{array}{l}1.00 \\
(0.91-1.10)\end{array}$ & $\begin{array}{l}1.00 \\
(0.92-1.09)\end{array}$ & 0.898 & $\begin{array}{l}1.24 \\
(0.99-1.55)\end{array}$ & $\begin{array}{l}0.91 \\
(0.76-1.09)\end{array}$ & 0.138 \\
\hline $\begin{array}{l}\text { Ischemic } \\
\text { stroke }\end{array}$ & $\begin{array}{l}1.08 \\
(1.02-1.14)\end{array}$ & $\begin{array}{l}1.06 \\
(1.02-1.10)\end{array}$ & 0.480 & $\begin{array}{l}1.05 \\
(1.00-1.11)\end{array}$ & $\begin{array}{l}1.08 \\
(1.04-1.13)\end{array}$ & 0.357 & $\begin{array}{l}1.19 \\
(1.06-1.35)\end{array}$ & $\begin{array}{l}1.05 \\
(0.97-1.13)\end{array}$ & 0.245 \\
\hline
\end{tabular}

Abbreviations: $\mathrm{Cl}=$ confidence interval; $\mathrm{CVD}=$ cardio-cerebral vascular disease; DDF = daytime dysfunction; DIMS = difficulties in initiating or maintaining sleep; EMA = early morning awakening; HR = hazard ratio; IHD = ischemic heart disease; MI = myocardial infarction.

${ }^{a}$ Model 3 was adopted to adjust for confounding factors. Male or female participants without the corresponding insomnia symptom were considered the reference group.

b The $p$ values for interaction were estimated by including an interaction term of the insomnia symptom and sex in model 3. 
Figure $1 \mathrm{HR}(95 \% \mathrm{Cl})$ of total and subtypes of CVD incidence according to number of insomnia symptoms

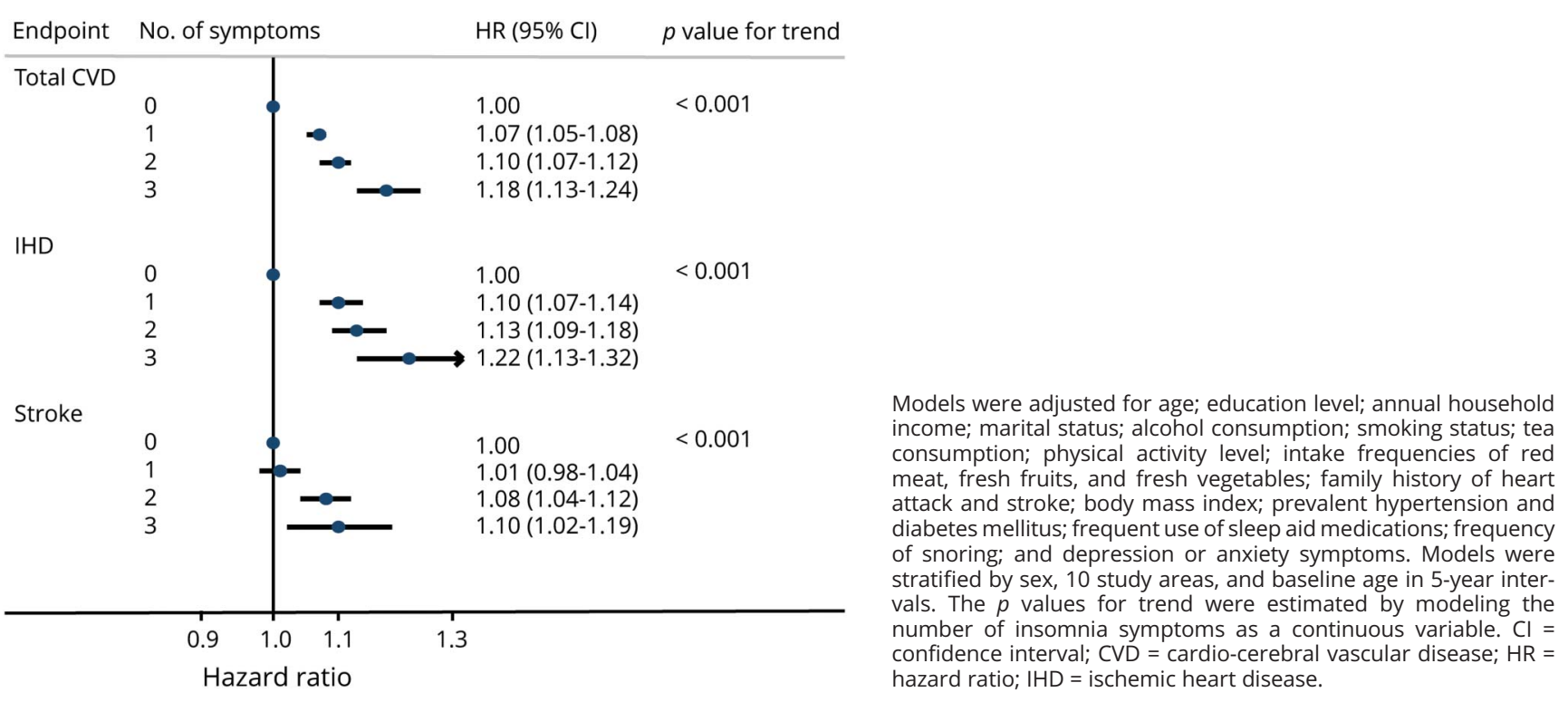

\section{Associations of any insomnia symptoms and number of insomnia symptoms with CVD incidence}

Overall, $16.4 \%$ of participants reported having any insomnia symptoms, and the proportions of participants reporting 1, 2, and 3 insomnia symptoms were $10.0 \%, 5.2 \%$, and $1.2 \%$, respectively. After adjustment for potential confounders, having any insomnia symptoms was associated with increased risks of total CVD, IHD, and total and ischemic stroke incidence; the respective HRs (95\% CIs) were 1.08 (1.07-1.10), 1.12 (1.09-1.15), 1.04 (1.02-1.07), and 1.06 (1.03-1.09).
Compared with those without any insomnia symptoms, participants with 1,2 , or 3 symptoms had a $7 \%, 10 \%$, or $18 \%$ higher risk of total CVD incidence, respectively $(p<0.05$, figure 1). A larger number of insomnia symptoms was associated with increased risk of total CVD incidence ( $p$ for trend $<0.001)$. Similar trends were also detected for incidences of IHD and total and ischemic strokes ( $p$ for trend $<0.05$ ).

\section{Subgroup analysis by baseline characteristics}

Results of subgroup analysis indicated that baseline age, BMI, and prevalent hypertension modified the associations

Figure $2 \mathrm{HR}(95 \% \mathrm{Cl})$ of total CVD incidence according to insomnia symptoms stratified by baseline characteristics

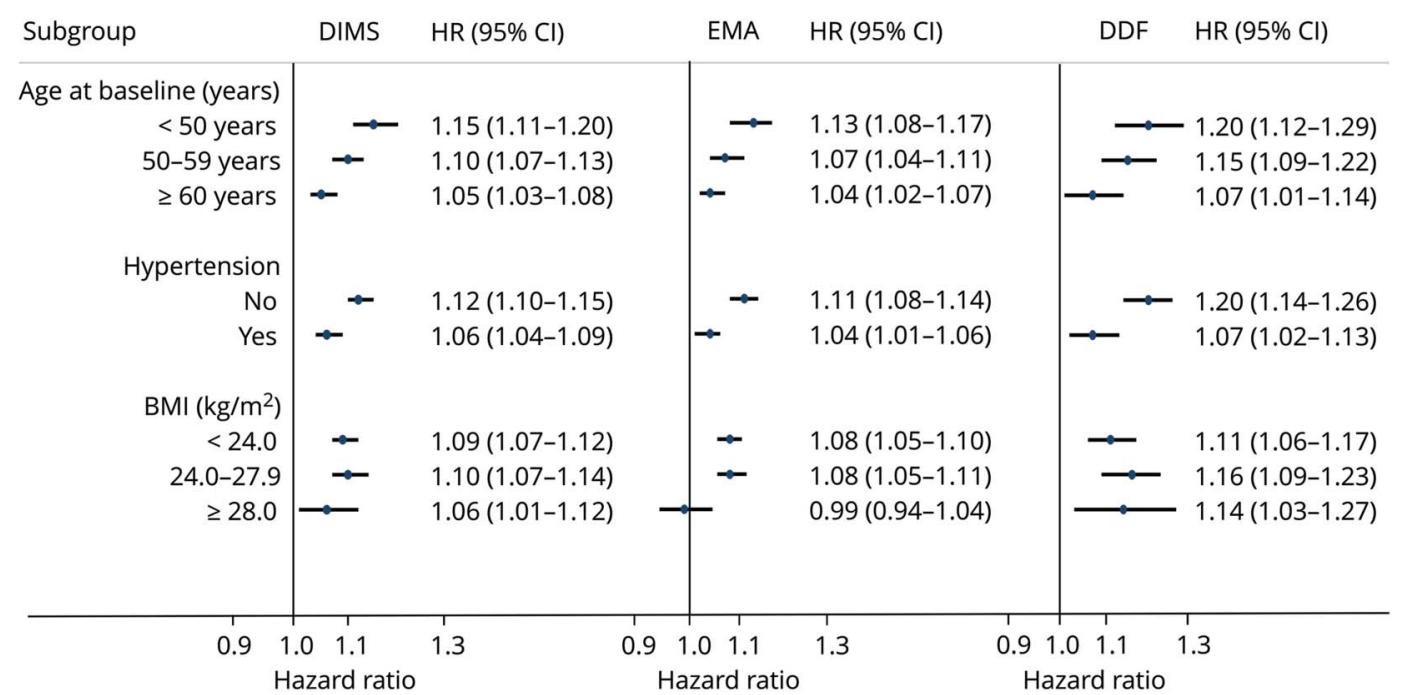

All $p$ values for interaction were $<0.05$ except for the interaction between daytime dysfunction (DDF) and body mass index (BMI). Model 3 was adopted to adjust for confounding factors. $\mathrm{Cl}$ = confidence interval; CVD = cardio-cerebral vascular disease; DIMS = difficulties in initiating or maintaining sleep; EMA = early morning awakening; $\mathrm{HR}=$ hazard ratio. 
between insomnia symptoms and total CVD incidence (figure 2). The associations of DIMS, EMA, and DDF with total CVD incidence were consistently stronger in younger participants $(p$ for interaction $<0.05$ ). Stronger associations for DIMS, EMA, and DDF were also identified in participants without hypertension at baseline ( $p$ for interaction $<0.05$ ). Compared with participants with obesity at baseline, normalweight or overweight participants had higher increments of CVD risks associated with DIMS and EMA ( $p$ for interaction $<0.05$ ). No effect modification was identified by sleep duration, physical activity level, or prevalent diabetes mellitus at baseline (data not shown).

\section{Discussion}

In this large-scale prospective study, we observed that the 3 insomnia symptoms of DIMS, EMA, and DDF were moderately associated with increased risks of total and specific types of CVD among Chinese adults. A positive dose-response relationship was identified between the number of insomnia symptoms and increased CVD risks. In addition, the associations between the 3 symptoms and CVD incidence were consistently more evident in younger adults or participants without hypertension at baseline.

Our study identified moderate associations between insomnia symptoms and total CVD incidence, which were consistent with findings from a number of previous cohort studies. ${ }^{6,18} \mathrm{~A}$ systematic review of 13 cohort studies with a combination of 122,501 participants indicated that insomnia disorder determined an increased risk of developing or dying of CVD (relative risk 1.45, 95\% CI 1.29-1.62). ${ }^{10}$ However, the comparability across those studies was compromised by the inconsistency in the definitions of insomnia. ${ }^{10}$ A previous study of 23,447 US men investigated associations between individual insomnia symptoms and CVD mortality. ${ }^{19}$ The results showed that men with difficulty initiating sleep or nonrestorative sleep most of the time had a $55 \%$ or $32 \%$ increased risk of CVD mortality. Another study of 13,227 Swedish adults found that affirming moderate or considerable problems with at least 1 of 4 insomnia symptoms was associated with increased CVD incidence only in women (HR 1.4, 95\% CI 1.2-1.6). ${ }^{13}$

As for risks of specific types of CVD, our results indicated that DIMS, EMA, and DDF were associated with increased risks of IHD incidence and total and ischemic stroke incidence. These results were in line with a systematic review that related insomnia to increased risks of $\mathrm{CHD}$ and stroke incidence (relative risk 1.28 and 1.55). ${ }^{9}$ Another cohort study of 52,610 Norwegian adults associated experiencing DIMS almost every night with an increase in acute MI incidence (HR 1.45 and $1.30) .{ }^{20}$ In our study, we also identified an association between DIMS and increased risk of acute MI incidence. Although a sufficient number of hemorrhagic stroke cases were observed during the follow-up time due to relatively high incidence rate among Asian population, ${ }^{21,22}$ we did not identify any associations between insomnia symptoms and hemorrhagic stroke incidence. This implied possible heterogeneity in the associations between insomnia and stroke subtypes, the underlying mechanisms of which warrant further research.

Sex heterogeneity was detected in the associations of insomnia symptoms with IHD and acute MI incidence. Similar to our results, the above-mentioned Norwegian cohort study also found that women had higher relative risks of acute $\mathrm{MI}$ associated with difficulties initiating sleep compared with men ( $p$ for heterogeneity $=0.009) .{ }^{20}$ Two Swedish cohort studies also found that difficulty maintaining sleep or any insomnia symptoms was associated with increased risks of cardiovascular events only in women. ${ }^{13,23}$ Such sex heterogeneity might be caused by different sleep characteristics or patterns between men and women ${ }^{24}$ or may be influenced by estrogen secretion in women. ${ }^{25}$

Our study is the first large-scale cohort study that identified positive dose-response relationships between the number of insomnia symptoms and risks of CVD, IHD, and stroke incidence. In contrast, a Finnish cohort study found no significant association between the number of insomnia symptoms and CHD incidence. ${ }^{26}$ The number of insomnia symptoms could reflect the severity of insomnia or complexity of underlying pathologies and thus was related to elevated CVD risks.

Results of subgroup analysis demonstrated that baseline age, $\mathrm{BMI}$, and prevalent hypertension modified the associations between insomnia symptoms and total CVD incidence. In line with our study, a Swedish cohort study of 41,192 adults identified a significant interaction between age and difficulty falling asleep on CVD incidence. ${ }^{23}$ Another cohort study of 85,752 adults also indicated that insomniacs-to-noninsomniacs incidence rate ratio of stroke was highest among young adults. ${ }^{7}$ One possible explanation for the moderating effects of BMI and baseline hypertension is that the relationship between insomnia and future CVD risk could be mediated through developing obesity and hypertension during follow-up. ${ }^{27,28}$ Therefore, the associations were weakened among participants with preexisting obesity or hypertension at baseline. The findings of attenuated associations in older adults could be explained by relatively higher baseline CVD risks among elderly participants or the fact that a larger proportion of elderly participants had already developed intermediate diseases or disorders (e.g., obesity, hypertension, or diabetes mellitus) at baseline.

Several proposed biological mechanisms relate insomnia to CVD risks. Previous experimental and epidemiologic studies suggested that insomnia was related to elevated levels of inflammatory cytokines ${ }^{29}$ and sympathetic nervous activation ${ }^{30}$ and could lead to metabolic and endocrine disruptions. ${ }^{31,32}$ There was also evidence that sleep deprivation or poor sleep quality was related to levels of leptin and ghrelin, which could result in obesity and impaired glucose tolerance. ${ }^{33}$ In addition, several previous studies related insomnia to the pathogenesis 
and intermediate risk factors of CVD such as atherosclerosis and high blood pressure. ${ }^{34,35}$ Our findings of moderating effects of prevalent hypertension and obesity provided supporting evidence for these mechanisms.

Our results implied that preclinical insomnia symptoms could be considered modifiable risk factors for subsequent CVD incidence. At present, the clinical diagnostic criteria for insomnia are inconsistent, ${ }^{16}$ and there is a lack of widely accepted criteria for the classification of insomnia phenotypes. ${ }^{36,37}$ In contrast, individual insomnia symptoms are better defined and more feasible to assess with questionnaires in large-scale population studies and clinical practice. Moreover, it is reasonable that insomnia symptoms are more modifiable and precisely targetable through behavioral therapies before developing into clinically significant insomnia disorder. ${ }^{38}$ Therefore, future clinical trials or community-based intervention studies should be conducted to test whether lifestyle or sleep hygiene interventions for insomnia symptoms can reduce subsequent CVD risks. ${ }^{8,39}$ This study also implied that adults with multiple insomnia symptoms are at even higher risk of developing CVDs; this dose-response relationship should draw clinical attention. The moderating effect of age revealed that, although insomnia is more prevalent in older adults, it is indeed more detrimental for young adults in terms of CVD risks. In the present study, DDF was not associated with ischemic stroke incidence after controlling for DIMS and EMA, implying different physiologic impacts and health consequences of specific insomnia symptoms. ${ }^{12}$

This study is the first-ever large cohort study to examine the associations of individual insomnia symptoms with CVD incidence among male and female adults, with plenty of established and potential confounding factors being controlled. However, this study still has several limitations. First, we did not collect information on nonrestorative sleep, which is another common insomnia symptom, ${ }^{1}$ during the baseline survey, whereas other insomnia symptoms were well collected and well defined with quantitative criteria. Second, the validity of self-reported insomnia symptoms in this study has not been fully examined. Therefore, our findings need to be interpreted with caution due to possible information bias. However, the potential misclassification of baseline insomnia symptoms in this study was unlikely to depend on future CVD incidence and thus could only bias the results toward the null hypotheses. Furthermore, this study could still suffer from residual confounding bias due to uncollected covariates. For example, shift work and obstructive sleep apnea are established risk factors for CHD or stroke $e^{40,41}$ and could interfere with insomnia symptoms. Nevertheless, we did assess snoring symptom in the baseline survey and have adjusted for it in the main analysis. Finally, insomnia symptoms were assessed only once at baseline survey, so we were unable to examine the associations while taking into account the changes in symptoms over time. Future research will be conducted using repeatedly measured exposure data from the resurvey of CKB Study.
This large-scale cohort study demonstrated that individual insomnia symptoms are independent risk factors of total CVD, IHD, and ischemic stroke. The associations could be modified by age and prevalent hypertension at baseline. Therefore, early detection and intervention targeted at individual insomnia symptoms may have the potential to reduce subsequent CVD risks, especially among young adults and adults who have not developed hypertension.

\section{Acknowledgment}

The authors thank the participants in the study and the members of the survey teams in each of the 10 regional centers, as well as the project development and management teams based in Beijing, Oxford, and the 10 regional centers.

\section{Study funding}

This study was supported by the National Key Research and Development Program of China (2016YFC0900500, 2016YFC0900501, 2016YFC0900504), the Chinese Ministry of Science and Technology (2011BAI09B01), and the National Natural Science Foundation of China (81390544, $81390541)$. The CKB baseline survey and the first resurvey were supported by a grant from the Kadoorie Charitable Foundation in Hong Kong, China. The long-term follow-up is supported by grants from the UK Wellcome Trust (088158/ Z/09/Z, 104085/Z/14/Z).

\section{Disclosure}

The authors report no disclosures relevant to the manuscript. Go to Neurology.org/N for full disclosures.

\section{Publication history}

Received by Neurology January 31, 2019. Accepted in final form July 5, 2019.

\begin{tabular}{llll} 
Appendix & Authors & & \\
\hline Name & Location & Role & Contribution \\
\hline $\begin{array}{l}\text { Bang } \\
\text { MSc }\end{array}$ & $\begin{array}{l}\text { Peking University, } \\
\text { China; Imperial } \\
\text { College London, UK }\end{array}$ & Author & $\begin{array}{l}\text { Design and } \\
\text { conceptualized study; } \\
\text { analyzed the data; } \\
\text { conducted the } \\
\text { analyses and drafted } \\
\text { the manuscript }\end{array}$ \\
\hline $\begin{array}{l}\text { Canqing Yu, } \\
\text { PhD }\end{array}$ & $\begin{array}{l}\text { Peking University, } \\
\text { China }\end{array}$ & Author & $\begin{array}{l}\text { Design and } \\
\text { conceptualized study; } \\
\text { drafted the } \\
\text { manuscript }\end{array}$ \\
\hline Jun Lv, PhD & $\begin{array}{l}\text { Peking University, } \\
\text { China }\end{array}$ & Author & $\begin{array}{l}\text { Critically reviewed and } \\
\text { revised the } \\
\text { manuscript }\end{array}$ \\
\hline $\begin{array}{l}\text { Yu Guo, } \\
\text { MSc }\end{array}$ & $\begin{array}{l}\text { Chinese Academy of } \\
\text { Medical Sciences, } \\
\text { Beijing }\end{array}$ & Author & $\begin{array}{l}\text { Collected the data; } \\
\text { conducted data } \\
\text { cleaning and case } \\
\text { verification }\end{array}$ \\
\hline $\begin{array}{l}\text { Zheng Bian, } \\
\text { MSc }\end{array}$ & $\begin{array}{l}\text { Chinese Academy of } \\
\text { Medical Sciences, } \\
\text { Beijing }\end{array}$ & Author & $\begin{array}{l}\text { Collected the data; } \\
\text { conducted data } \\
\text { cleaning and case } \\
\text { verification }\end{array}$ \\
\hline & and & &
\end{tabular}

Continued 
Appendix (continued)

\begin{tabular}{|c|c|c|c|}
\hline Name & Location & Role & Contribution \\
\hline $\begin{array}{l}\text { Mi Zhou, } \\
\text { BSc }\end{array}$ & $\begin{array}{l}\text { Peking University, } \\
\text { China }\end{array}$ & Author & $\begin{array}{l}\text { Conducted analyses } \\
\text { and data review }\end{array}$ \\
\hline $\begin{array}{l}\text { Ling Yang, } \\
\text { PhD }\end{array}$ & $\begin{array}{l}\text { University of Oxford, } \\
\text { UK }\end{array}$ & Author & $\begin{array}{l}\text { Conducted data } \\
\text { cleaning and case } \\
\text { verification }\end{array}$ \\
\hline $\begin{array}{l}\text { Yiping } \\
\text { Chen, DPhil }\end{array}$ & $\begin{array}{l}\text { University of Oxford, } \\
\text { UK }\end{array}$ & Author & $\begin{array}{l}\text { Conducted data } \\
\text { cleaning and case } \\
\text { verification }\end{array}$ \\
\hline $\begin{array}{l}\text { Xiaojun Li, } \\
\text { BSc }\end{array}$ & $\begin{array}{l}\text { Jili Community Health } \\
\text { Service, Liuyang, } \\
\text { Hunan, China }\end{array}$ & Author & Collected the data \\
\hline Ju Zou, BSc & $\begin{array}{l}\text { Jili Community Health } \\
\text { Service, Liuyang, } \\
\text { Hunan, China }\end{array}$ & Author & Collected the data \\
\hline $\begin{array}{l}\text { Feng Ning, } \\
\text { PhD }\end{array}$ & $\begin{array}{l}\text { Qingdao Center for } \\
\text { Disease Control and } \\
\text { Prevention, } \\
\text { Shandong, China }\end{array}$ & Author & Collected the data \\
\hline $\begin{array}{l}\text { Junshi } \\
\text { Chen, MD }\end{array}$ & $\begin{array}{l}\text { China National } \\
\text { Center for Food } \\
\text { Safety Risk } \\
\text { Assessment, Beijing }\end{array}$ & Author & $\begin{array}{l}\text { Critically reviewed and } \\
\text { revised the } \\
\text { manuscript }\end{array}$ \\
\hline $\begin{array}{l}\text { Zhengming } \\
\text { Chen, DPhil }\end{array}$ & $\begin{array}{l}\text { University of Oxford, } \\
\text { UK }\end{array}$ & Author & $\begin{array}{l}\text { Critically reviewed and } \\
\text { revised the } \\
\text { manuscript }\end{array}$ \\
\hline $\begin{array}{l}\text { Liming Li, } \\
\text { MD }\end{array}$ & $\begin{array}{l}\text { Peking University, } \\
\text { China; Chinese } \\
\text { Academy of Medical } \\
\text { Sciences, Beijing }\end{array}$ & Author & $\begin{array}{l}\text { Design and } \\
\text { conceptualized study; } \\
\text { revised the } \\
\text { manuscript; major } \\
\text { role in the acquisition } \\
\text { of data; guarantor of } \\
\text { the study }\end{array}$ \\
\hline
\end{tabular}

\section{References}

1. Sateia MJ. International Classification of Sleep Disorders-Third Edition: highlights and modifications. Chest 2014;146:1387-1394.

2. Sateia MJ, Doghramji K, Hauri PJ, Morin CM. Evaluation of chronic insomnia: an American Academy of Sleep Medicine review. Sleep 2000;23:243-308.

3. Ohayon MM. Epidemiology of insomnia: what we know and what we still need to learn. Sleep Med Rev 2002;6:97-111.

4. Yin $\mathrm{P}$, Zhang M, Li Y, Jiang Y, Wang L, Zhao W. A study on risk factors for poor sleep quality among Chinese residents aged 15-69 years [in Chinese]. Chin J Prev Contr Chron Dis 2011;19:224-225.

5. Fernandez-Mendoza J, Vgontzas AN. Insomnia and its impact on physical and mental health. Curr Psychiatry Rep 2013;15:418.

6. Chien $\mathrm{KL}$, Chen PC, Hsu HC, et al. Habitual sleep duration and insomnia and the risk of cardiovascular events and all-cause death: report from a community-based cohort. Sleep 2010;33:177-184.

7. Wu MP, Lin HJ, Weng SF, Ho CH, Wang JJ, Hsu YW. Insomnia subtypes and the subsequent risks of stroke: report from a nationally representative cohort. Stroke 2014:45:1349-1354.

8. St-Onge MP, Grandner MA, Brown D, et al. Sleep duration and quality: impact on lifestyle behaviors and cardiometabolic health: a scientific statement from the American Heart Association. Circulation 2016;134:e367-e386.

9. Li M, Zhang XW, Hou WS, Tang ZY. Insomnia and risk of cardiovascular disease: a meta-analysis of cohort studies. Int J Cardiol 2014;176:1044-1047.

10. Sofi F, Cesari F, Casini A, Macchi C, Abbate R, Gensini GF. Insomnia and risk of cardiovascular disease: a meta-analysis. Eur J Prev Cardiol 2014;21:57-64.

11. Lack LC, Mercer JD, Wright H. Circadian rhythms of early morning awakening insomniacs. J Sleep Res 1996;5:211-219.

12. Zhang J, Lamers F, Hickie IB, He JP, Feig E, Merikangas KR. Differentiating nonrestorative sleep from nocturnal insomnia symptoms: demographic, clinical, inflammatory, and functional correlates. Sleep 2013;36:671-679.
13. Canivet C, Nilsson PM, Lindeberg SI, Karasek R, Ostergren PO. Insomnia increases risk for cardiovascular events in women and in men with low socioeconomic status: a longitudinal, register-based study. J Psychosom Res 2014;76:292-299.

14. Chen Z, Lee L, Chen J, et al. Cohort profile: the Kadoorie Study of Chronic Disease in China (KSCDC). Int J Epidemiol 2005;34:1243-1249.

15. Chen Z, Chen J, Collins R, et al. China Kadoorie Biobank of 0.5 million people: survey methods, baseline characteristics and long-term follow-up. Int J Epidemiol 2011;40: $1652-1666$

16. Chung KF, Yeung WF, Ho FY, Yung KP, Yu YM, Kwok CW. Cross-cultural and comparative epidemiology of insomnia: the Diagnostic and Statistical Manual (DSM), International Classification of Diseases (ICD) and International Classification of Sleep Disorders (ICSD). Sleep Med 2015;16:477-482.

17. Hirshkowitz M, Whiton K, Albert SM, et al. National Sleep Foundation's updated sleep duration recommendations: final report. Sleep Health 2015;1:233-243.

18. Chandola T, Ferrie JE, Perski A, Akbaraly T, Marmot MG. The effect of short sleep duration on coronary heart disease risk is greatest among those with sleep disturbance: a prospective study from the Whitehall II cohort. Sleep 2010;33 739-744.

19. Li Y, Zhang X, Winkelman JW, et al. Association between insomnia symptoms and mortality: a prospective study of U.S. men. Circulation 2014;129:737-746.

20. Laugsand LE, Vatten LJ, Platou C, Janszky I. Insomnia and the risk of acute myocardial infarction: a population study. Circulation 2011;124:2073-2081.

21. van Asch CJ, Luitse MJ, Rinkel GJ, van der Tweel I, Algra A, Klijn CJ. Incidence, case fatality, and functional outcome of intracerebral haemorrhage over time, according to age, sex, and ethnic origin: a systematic review and meta-analysis. Lancet Neurol 2010 ; 9:167-176.

22. Burke TA, Venketasubramanian RN. The epidemiology of stroke in the East Asian region: a literature-based review. Int J Stroke 2006;1:208-215.

23. Westerlund A, Bellocco R, Sundstrom J, Adami HO, Akerstedt T, Trolle LY. Sleep characteristics and cardiovascular events in a large Swedish cohort. Eur J Epidemiol 2013;28:463-473.

24. Li RH, Wing YK, Ho SC, Fong SY. Gender differences in insomnia: a study in the Hong Kong Chinese population. J Psychosom Res 2002;53:601-609.

25. Vitiello MV, Larsen LH, Moe KE. Age-related sleep change: gender and estrogen effects on the subjective-objective sleep quality relationships of healthy, noncomplaining older men and women. J Psychosom Res 2004;56:503-510.

26. Loponen M, Hublin C, Kalimo R, Manttari M, Tenkanen L. Joint effect of selfreported sleep problems and three components of the metabolic syndrome on risk of coronary heart disease. J Psychosom Res 2010;68:149-158.

27. Grandner MA, Jackson NJ, Pak VM, Gehrman PR. Sleep disturbance is associated with cardiovascular and metabolic disorders. J Sleep Res 2012;21:427-433.

28. Meng L, Zheng Y, Hui R. The relationship of sleep duration and insomnia to risk of hypertension incidence: a meta-analysis of prospective cohort studies. Hypertens Res 2013;36:985-995.

29. Irwin MR, Olmstead R, Carroll JE. Sleep disturbance, sleep duration, and inflammation: a systematic review and meta-analysis of cohort studies and experimental sleep deprivation. Biol Psychiatry 2016;80:40-52.

30. Nilsson PM, Nilsson JA, Hedblad B, Berglund G. Sleep disturbance in association with elevated pulse rate for prediction of mortality: consequences of mental strain?.J Intern Med 2001;250:521-529.

31. Mullington JM, Haack M, Toth M, Serrador JM, Meier-Ewert HK. Cardiovascular, inflammatory, and metabolic consequences of sleep deprivation. Prog Cardiovasc Dis 2009;51:294-302.

32. Spiegel K, Leproult R, Van Cauter E. Impact of sleep debt on metabolic and endocrine function. Lancet 1999;354:1435-1439.

33. Knutson KL, Van Cauter E. Associations between sleep loss and increased risk of obesity and diabetes. Ann NY Acad Sci 2008;1129:287-304.

34. Nakazaki C, Noda A, Koike Y, Yamada S, Murohara T, Ozaki N. Association of insomnia and short sleep duration with atherosclerosis risk in the elderly. Am J Hypertens 2012;25:1149-1155

35. Vgontzas AN, Liao D, Bixler EO, Chrousos GP, Vela-Bueno A. Insomnia with objective short sleep duration is associated with a high risk for hypertension. Sleep 2009; 32:491-497.

36. Edinger JD, Bonnet $\mathrm{MH}$, Bootzin RR, et al. Derivation of research diagnostic criteria for insomnia: report of an American Academy of Sleep Medicine Work Group. Sleep 2004;27:1567-1596.

37. Edinger JD, Wyatt JK, Stepanski EJ, et al. Testing the reliability and validity of DSM IV-TR and ICSD-2 insomnia diagnoses: results of a multitrait-multimethod analysis Arch Gen Psychiatry 2011;68:992-1002.

38. Qaseem A, Kansagara D, Forciea MA, Cooke M, Denberg TD. Management of chronic insomnia disorder in adults: a clinical practice guideline from the American College of Physicians. Ann Intern Med 2016;165:125-133.

39. Rozanski A. Behavioral cardiology: current advances and future directions. J Am Coll Cardiol 2014;64:100-110.

40. Javaheri S, Barbe F, Campos-Rodriguez F, et al. Sleep apnea: types, mechanisms, and clinical cardiovascular consequences. J Am Coll Cardiol 2017;69:841-858.

41. Wang D, Ruan W, Chen Z, Peng Y, Li W. Shift work and risk of cardiovascular disease morbidity and mortality: a dose-response meta-analysis of cohort studies. Eur J Prev Cardiol 2018;25:1293-1302. 


\section{Neurology}

\section{Insomnia symptoms and risk of cardiovascular diseases among 0.5 million adults: A 10-year cohort \\ Bang Zheng, Canqing Yu, Jun Lv, et al.}

Neurology 2019;93;e2110-e2120 Published Online before print November 6, 2019

DOI 10.1212/WNL.0000000000008581

\section{This information is current as of November 6, 2019}

\section{Updated Information \&} Services

References

Citations

Subspecialty Collections

Permissions \& Licensing

Reprints including high resolution figures, can be found at: http://n.neurology.org/content/93/23/e2110.full

This article cites 41 articles, 6 of which you can access for free at: http://n.neurology.org/content/93/23/e2110.full\#ref-list-1

This article has been cited by 1 HighWire-hosted articles: http://n.neurology.org/content/93/23/e2110.full\#\#otherarticles

This article, along with others on similar topics, appears in the following collection(s):

\section{All Cerebrovascular disease/Stroke}

http://n.neurology.org/cgi/collection/all_cerebrovascular_disease_strok e

Cardiac

http://n.neurology.org/cgi/collection/cardiac

Cohort studies

http://n.neurology.org/cgi/collection/cohort_studies

Insomnia

http://n.neurology.org/cgi/collection/insomnia

Information about reproducing this article in parts (figures,tables) or in its entirety can be found online at:

http://www.neurology.org/about/about_the_journal\#permissions

Information about ordering reprints can be found online:

http://n.neurology.org/subscribers/advertise

Neurology ${ }^{\circledR}$ is the official journal of the American Academy of Neurology. Published continuously since 1951, it is now a weekly with 48 issues per year. Copyright Copyright (C) 2019 The Author(s). Published by Wolters Kluwer Health, Inc. on behalf of the American Academy of Neurology.. All rights reserved. Print ISSN: 0028-3878. Online ISSN: 1526-632X.

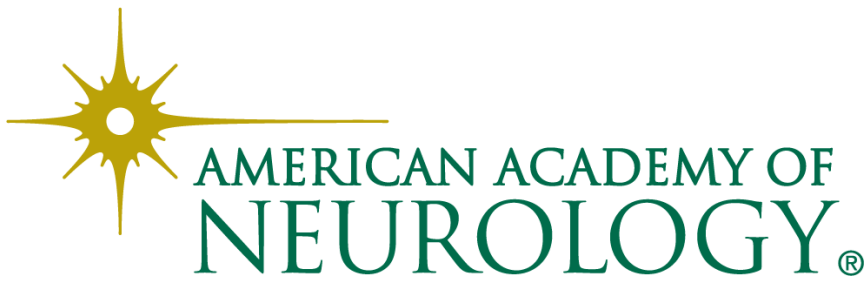

